\title{
Social and epidemiological research on alcohol: Research presented at meetings of the Kettil Bruun Society between 1983 and 2010
}

\author{
Henk Garretsen', Miranda Audenaerdt', len van de Goor', Diana Roeg', Rosalie van der Sar', \\ Tim Schoenmakers ${ }^{2}$ and Dike van de Mheen $^{2}$ \\ 1 Tranzo/Tilburg University, Addiction Research Institute (IVO Tilburg), Netherlands \\ 2 Addiction Research Institute Erasmus University Rotterdam (IVO Rotterdam), Netherlands
}

\begin{abstract}
Aims: To study developments in the research agenda on social and epidemiological research on alcohol between 1983 and 2010, as presented at meetings of the Kettil Bruun Society (KBS).

Design and setting: All papers presented at all annual meetings of the KBS between 1983 and 1993 are reviewed with regard to the content of the papers, the research methods used, the country of origin and demographic characteristics of the presenters. KBS papers from the years 2002/2003 and 2009/2010 are compared with those from 1983 to 1993 to determine changes in research authorship, methodology and/or focus.

Results and conclusions: Both in the period 1983 to 1993 and in the years 2002/2003 and 2009/2010, many papers describe general drinking patterns and/or alcohol problems. In all three research periods approximately $40 \%$ of the papers are based on surveys. However, some clear changes can be distinguished with regard to the research fields addressed and the research methods used. There seems to be increasing attention to multi-method studies and the combination of quantitative and qualitative research. In addition, methodologies have become more advanced and more varied over the years. Results show a continuous increase in the number of researchers (particularly female) submitting papers. Between 1983 and 1993 almost all participants came from North America (the United States and Canada) and Europe, especially the Nordic countries. In 2009/2010 researchers from many more countries were involved.
\end{abstract}

The research presented at annual meetings of the Kettil Bruun Society for Social and Epidemiological Research on Alcohol (KBS), the international society for this type of research, gives a good overview of the developments in the research agenda in this field. The KBS is an independent society open to all scientists working in the field. The society is based upon individual membership, but research institutions also have the opportunity to join as members. The aim is to promote social and epidemiological research that fosters a comparative understanding of the social aspects of alcohol use and alcohol problems (Demers, Garretsen, Room, Rosson, \& Ugland, 2004). The society also aims at promoting a spirit of international cooperation.

KBS is the successor of the epidemiology section of the International Council on Alcohol and Addictions. In 1987 this section joined the

Correspondence: Henk F. L. Garretsen, Professor Health Care Policy, Director Department Tranzo, Tilburg University, PO Box 90I53,

5000 LE Tilburg, Netherlands

Phone: +3I I3 466 3299/2969

Fax: +3I I3 4663637

E-mail: h.garretsen@uvt.nl

No financial support

Keywords: alcohol research, alcohol epidemiology, Kettil Bruun Society 
International Group for Comparative Alcohol Studies in establishing the then newly established Kettil Bruun Society, named after one of the pioneers in social alcohol research. The core activity of the society is a five-day annual meeting. In 20II, the $37^{\text {th }}$ annual meeting was organized in Melbourne, Australia (24 years of annual KBS meetings plus I3 years of its predecessor's meetings). Most participants at meetings present pre-circulated papers, which are discussed by assigned discussants and by the other participants. In addition, thematic meetings focusing on specified topics are organized, and KBS acts as a platform for organizing projects requiring international co-operation.

This article is the third overview paper in which the developments within the annual meetings are described. In I993, a paper was presented in which the developments in the annual meetings between I983 and I993 were described (Garretsen, van Oers, \& van de Goor, I993). These developments were studied by comparing the content of the papers presented at these annual meetings, research methods used in the papers, and the country of origin and gender of all participants. A second paper presented in 2003 investigated whether important changes had occurred Io years later, through a comparison of topics addressed and research methods used in 2002/2003 versus the period I983 to I993 (Garretsen, Bongers, van de Goor, \& Roeg, 2003). This article compares the period I983 to I993 with the years $2002 / 2003$ and $2009 / 2010$, again examining whether changes have occurred in the content of the papers and the research methods used.

\section{Method}

\section{Annual meetings and papers included in the study}

All annual meetings between 1983 and 1993 were included, plus those in 2002/2003 and 2009/2010. The number of participants and their country of origin is influenced by the location of the annual meeting and, as a consequence, the years 2002/2003 and $2009 / 2010$ were chosen because the locations of the host cities (in Europe) are comparable with most other KBS meetings.

For the meetings between I983 and I993, all papers actually presented in the main program were reviewed for this article. For the other years, all pa- pers included in the abstract lists were reviewed. This divergent approach could lead to a very small overestimation, as in some exceptional cases an abstract was submitted but the paper was not actually presented.

During many annual meetings, presymposia have been organized, focusing on specific issues such as qualitative research, or gender and alcohol. Papers presented in pre-symposia have not been included, although papers from pre-symposia that were also presented in the main program are included.

\section{Review process}

Analyses were conducted using abstracts of the papers. If the abstract lacked necessary information, the whole paper was studied. All abstracts/papers were analyzed by two researchers, independently of each other. When the two analyses did not match, the researchers discussed the paper in order to reach consensus. In the case of differing opinions, the final judgment was made by the principal investigator. All the researchers involved in the reviewing process are experienced in the field and have participated in several annual meetings.

\section{Measurement of the content of the papers}

To compare all papers from I983 onwards, it was necessary to use the same categories and criteria that had been used in the first paper (Garretsen et al., I993). Twelve categories were used to describe the content/subject of the papers presented: drinking patterns, drinking problems, methodology, explanatory models, alcohol and suicide, treatment and care, self-help groups, policy and prevention, norms and attitudes, women and alcohol, historical studies, and alcohol and drugs.

The content of each paper was assigned to one of the above categories. When the content fell into two or more categories, the general rule was to choose the category that was the least "popular" in I983, in terms of how many times it was scored. For example, if a paper applied to both drinking patterns and drinking problems, the paper was scored in the less popular category of drinking problems. If the content of a paper fell under drinking patterns and/or drinking problems on the one hand, and one of the other categories mentioned on the other, then the paper was scored in the other category involved. If a paper applied to two of the "other" categories than the category which applied most was chosen. If 
no decision could be made, the paper was scored in the less popular category.

\section{Measurement of the research methods used in the papers}

Five categories were used to describe the research methods used in the papers: surveys, existing data sources, qualitative methods/interviews, literature studies/reviews and "other." In the first two review papers (Garretsen et al., I993; 2003), the category "other" was scored when the method used was unknown/not described, or when papers described multimethod studies. For 2009/2010, a distinction was made between "multi-method studies" and "other" (the latter including methods unknown/not described). However, to compare 2009/2010 with the previous years, the categories "multi-method studies" and "other" were combined again.

\section{Country of origin and gender of the participants}

The country of origin and gender of all meeting participants were recorded. The country of origin was determined by the country of research affiliation of the first author involved. Countries were geographically grouped using the following categories: U.S.A./Canada, Nordic countries (Norway, Sweden, Finland, Denmark, Iceland), United Kingdom and
Ireland, "Mid-Europe" (Netherlands, Germany, Switzerland, Austria), "Southern Europe" (France, Italy, Spain, Portugal) and "Eastern Europe" (Hungary, Poland, Czech Republic, Yugoslavia/Croatia/Bosnia and Herzegovina, Lithuania, Russia) and "Other."

These categories are based on the situation described in the first paper (Garretsen et al., I993). In those days most participants came from Europe and the U.S.A./Canada. Now this situation has changed to a large extent. For this reason, for $2009 / 2010$ the category "Other" was replaced by the categories Australia/New Zealand, South and Central America, Asia, and Africa. However, for the purposes of comparing 2009/2010 with the previous years, these new categories were combined again into "Other."

\section{Results}

The number of papers presented has increased considerably over the years (Figure I). In I983, 35 papers were presented at the annual meeting held in Padua, Italy. The number of papers had more than doubled by the I988 annual meeting held in Berkeley, United States. The number of papers presented in $2009(N=$ I78) and $2010(N=\mathrm{I} 60)$ was in turn much higher than in earlier years.

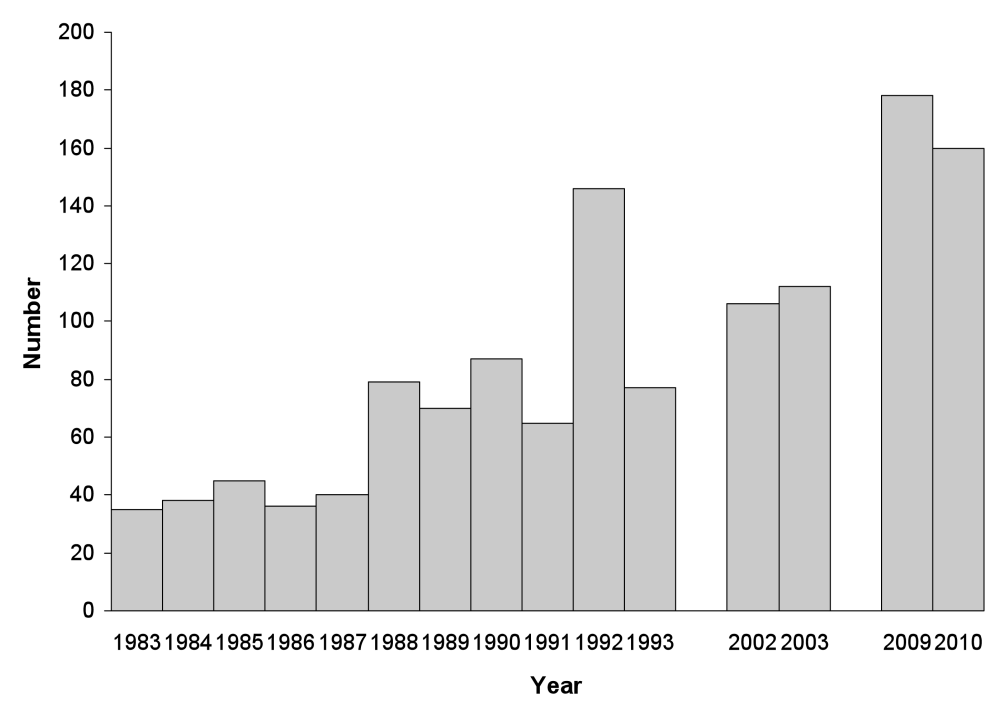

Figure 1: Absolute number of papers 


\section{Content}

In $2009 / 2010$ most papers dealt with drinking patterns and/or drinking problems, policy, explanatory models, norms and attitudes, treatment and care, and drugs (Figure 2). Many papers described general drinking patterns and/or alcohol problems (Figures 3 and 4). This is true for all years studied, although some clear changes can be distinguished. Compared to the years I983 to I993, more papers in $2002 / 2003$ and $2009 / 2010$ dealt with policy (Figure 5). In $2009 / 2010,17 \%$ of papers dealt with this topic, versus an average of $10 \%$ between 1983 and I993. An increase in the number of papers on explanatory models can also be seen in 2009/2010 (Figure 6). The topics "treatment and care" and "norms and attitudes" were a little more prevalent in $2002 / 2003$ and in $2009 / 2010$, compared to the period I983 to 1993. The percentage of papers on drugs (and on drugs and alcohol together) fluctuated over the years.

A number of topics were only prevalent in a limited number of years. For example, papers on self-help groups and alcohol and suicide were prevalent around I990, while papers focusing on women and alcohol and historical studies were prevalent in I984 and I985 respectively. (Figures 7-I4).

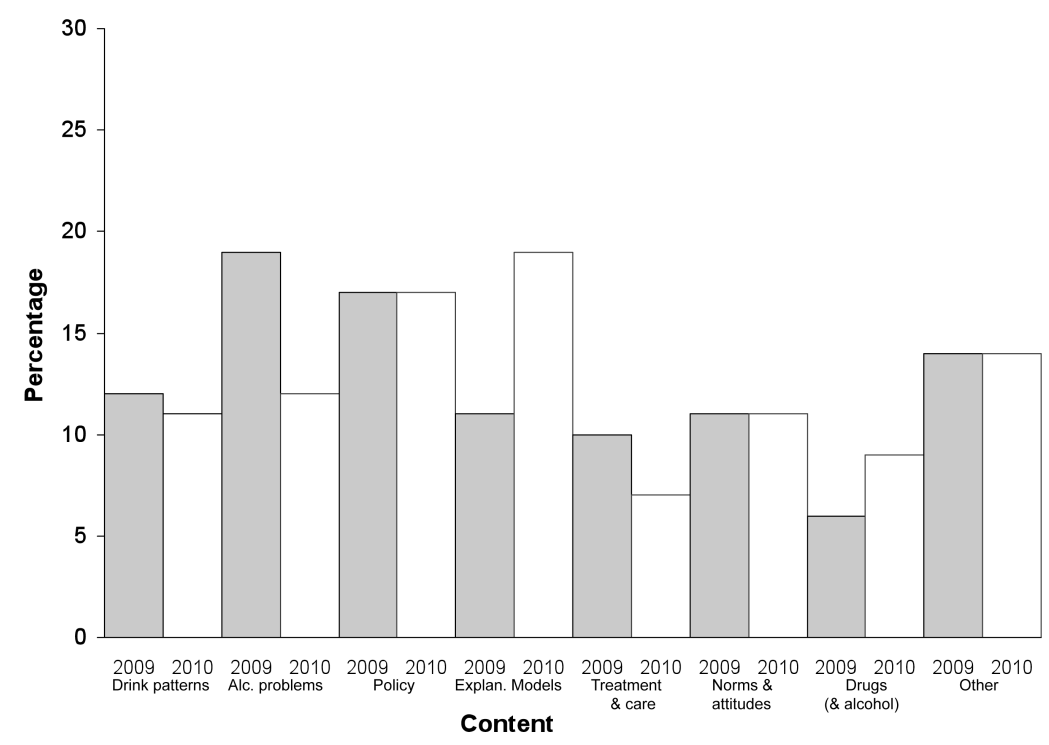

Figure 2: Content of the papers 2009/2010 


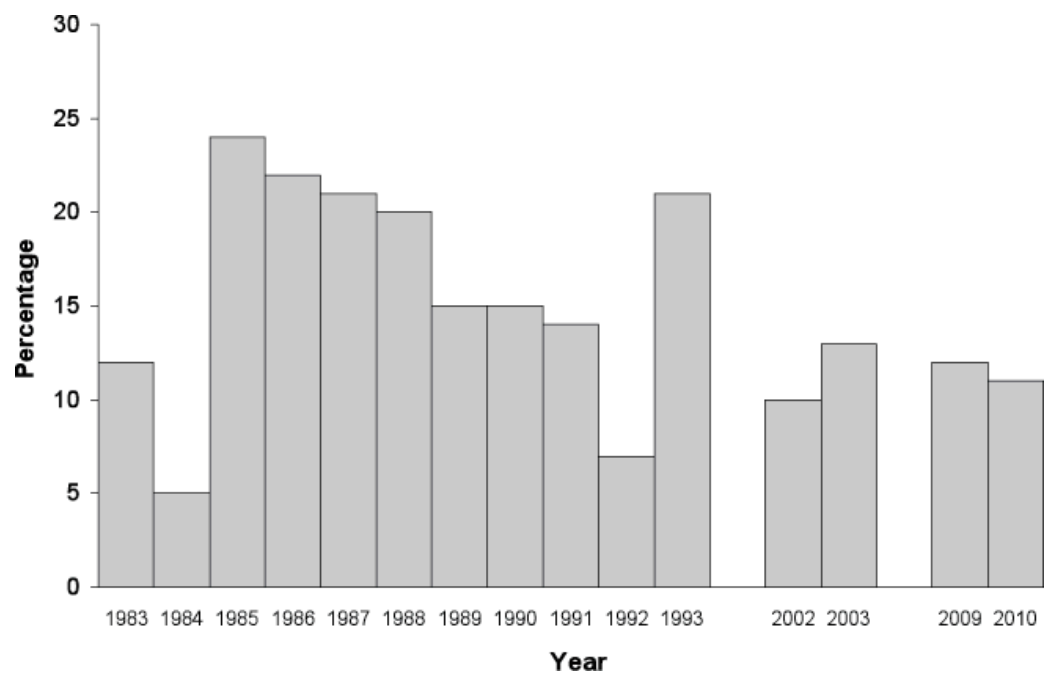

Figure 3: Percentage of papers on drinking patterns

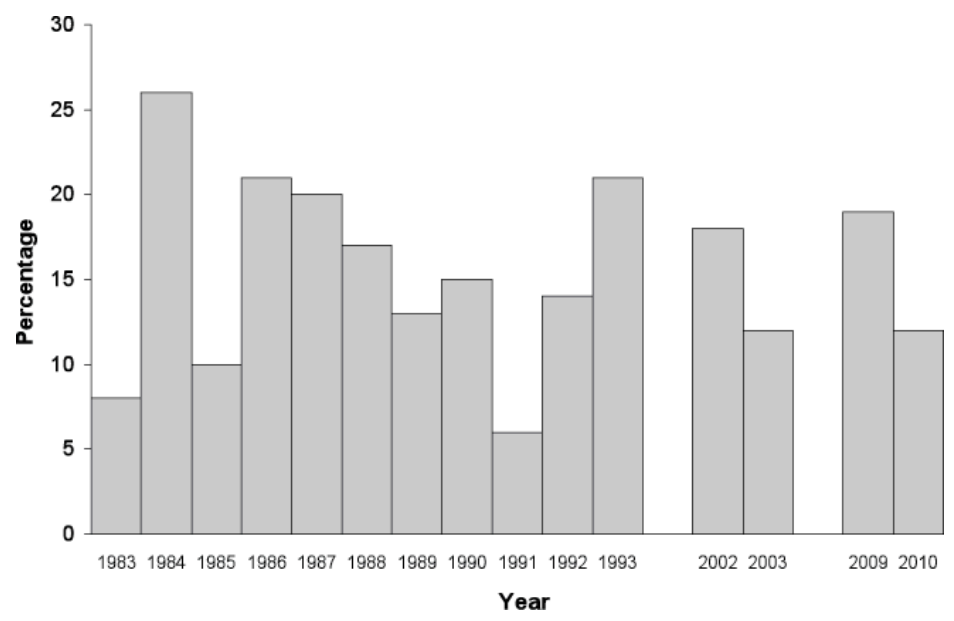

Figure 4: Percentage of papers on alcohol problems 


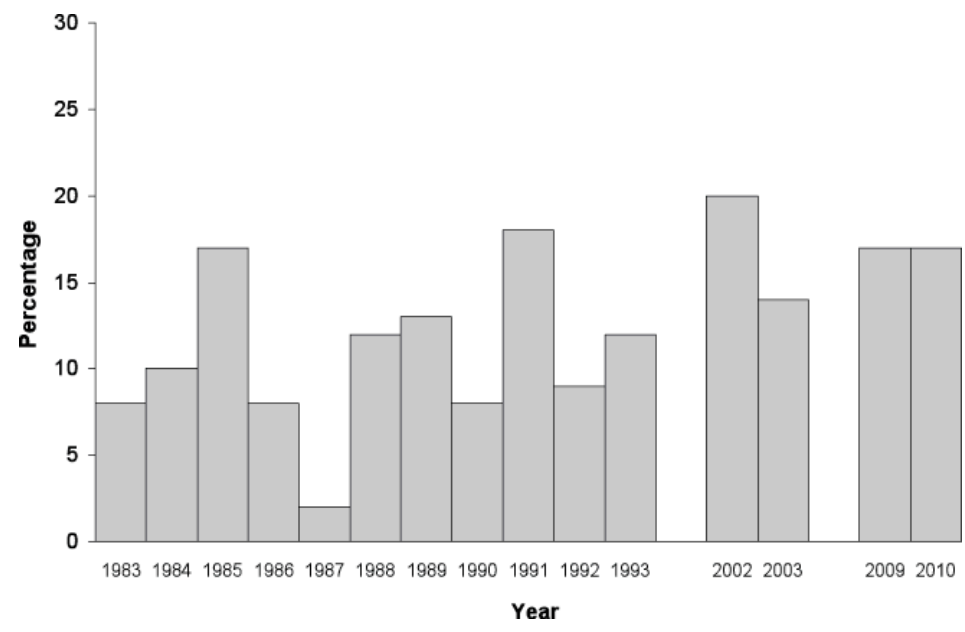

Figure 5: Percentage of papers on policy

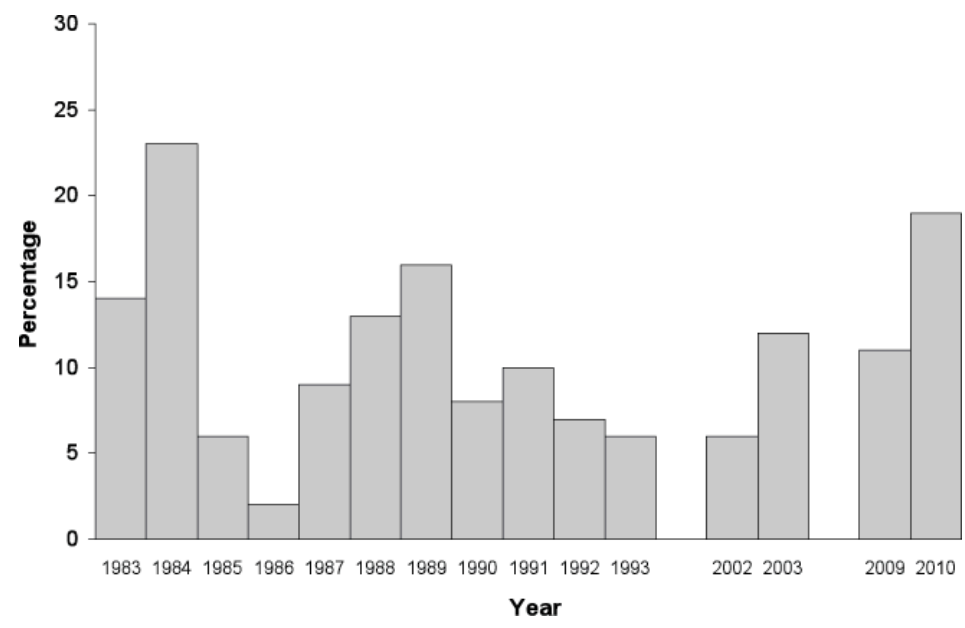

Figure 6: Percentage of papers on explanatory models 


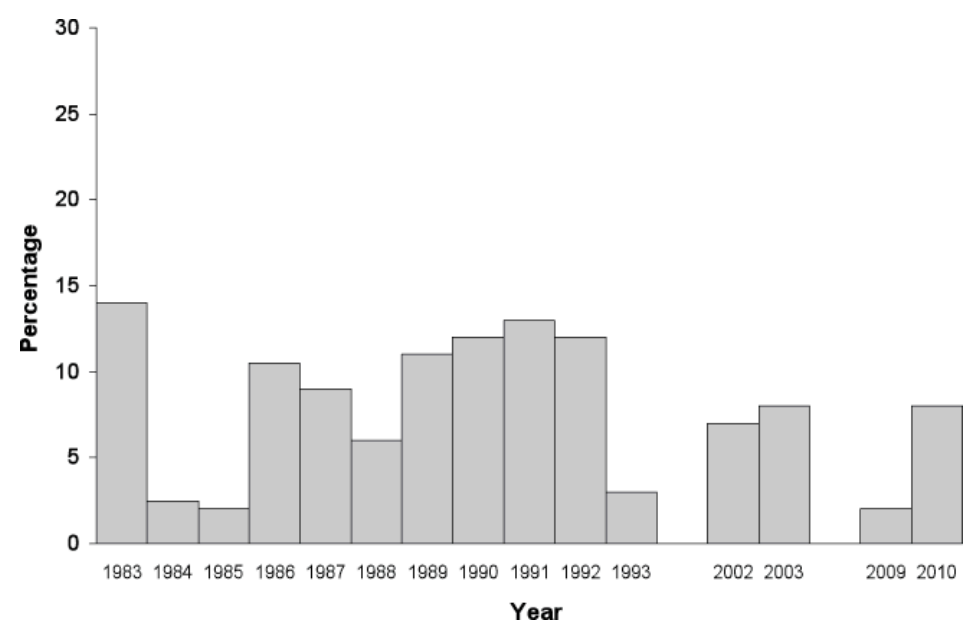

Figure 7: Percentage of papers on methodology

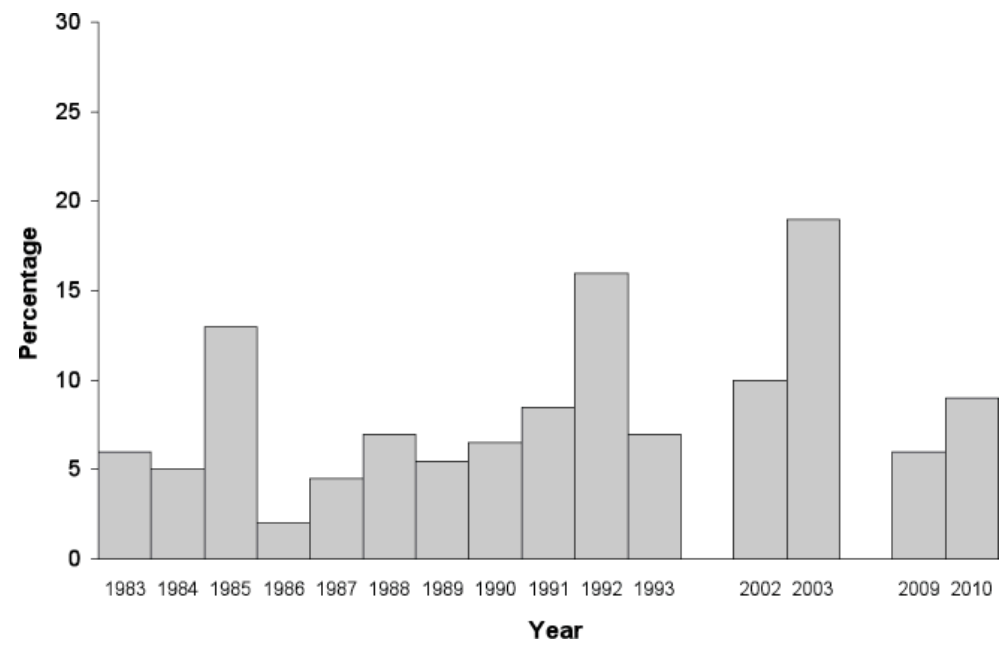

Figure 8: Percentage of papers on drugs and alcohol 


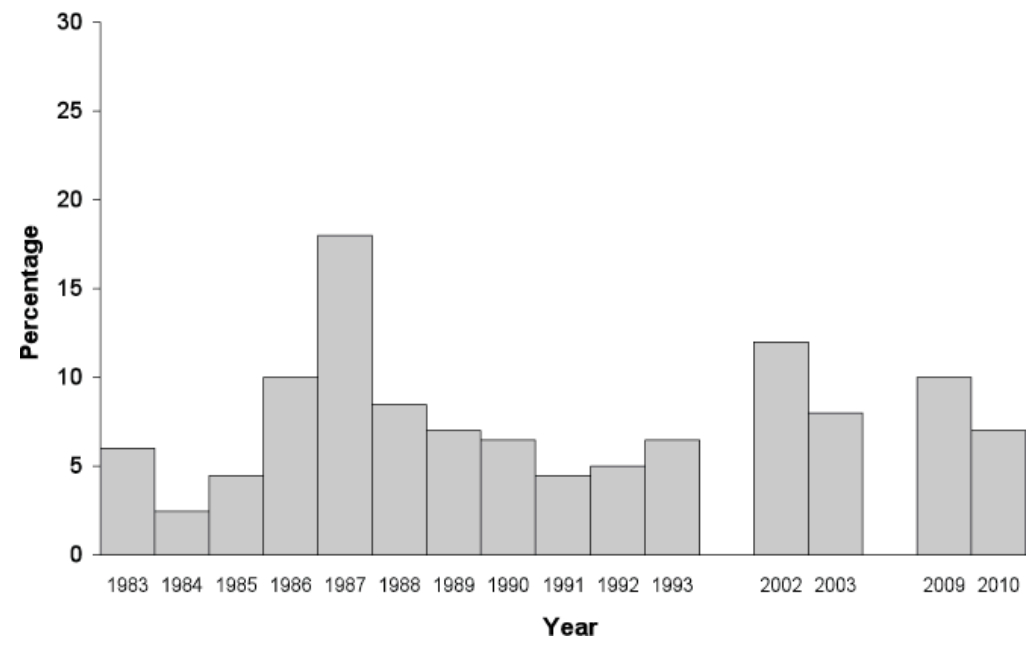

Figure 9: Percentage of papers on treatment and care

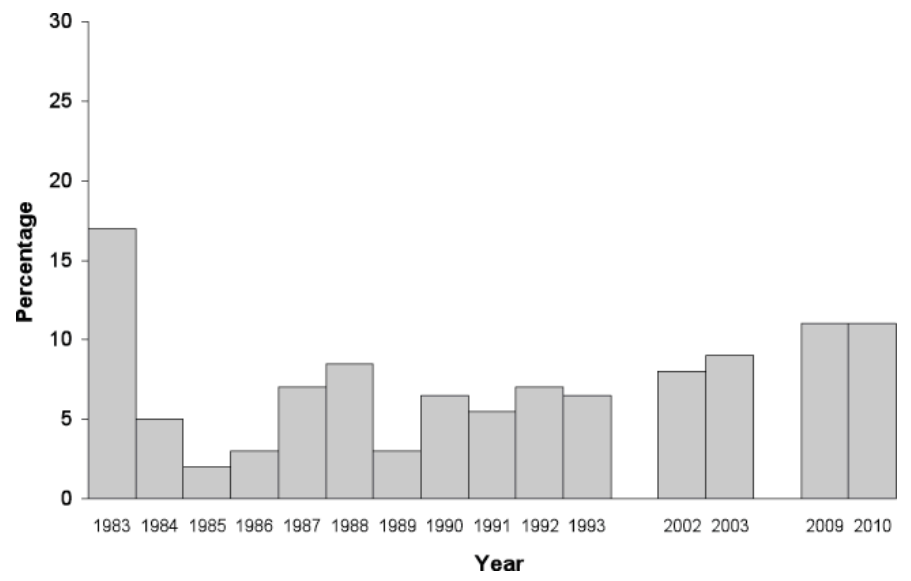

Figure 10: Percentage of papers on norms and attitudes 


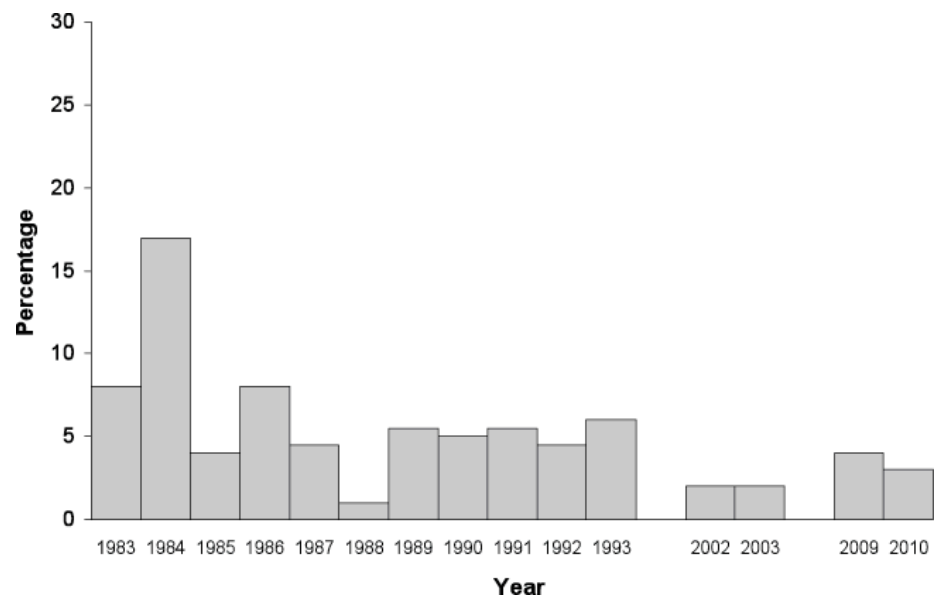

Figure 11: Percentage of papers on women and alcohol

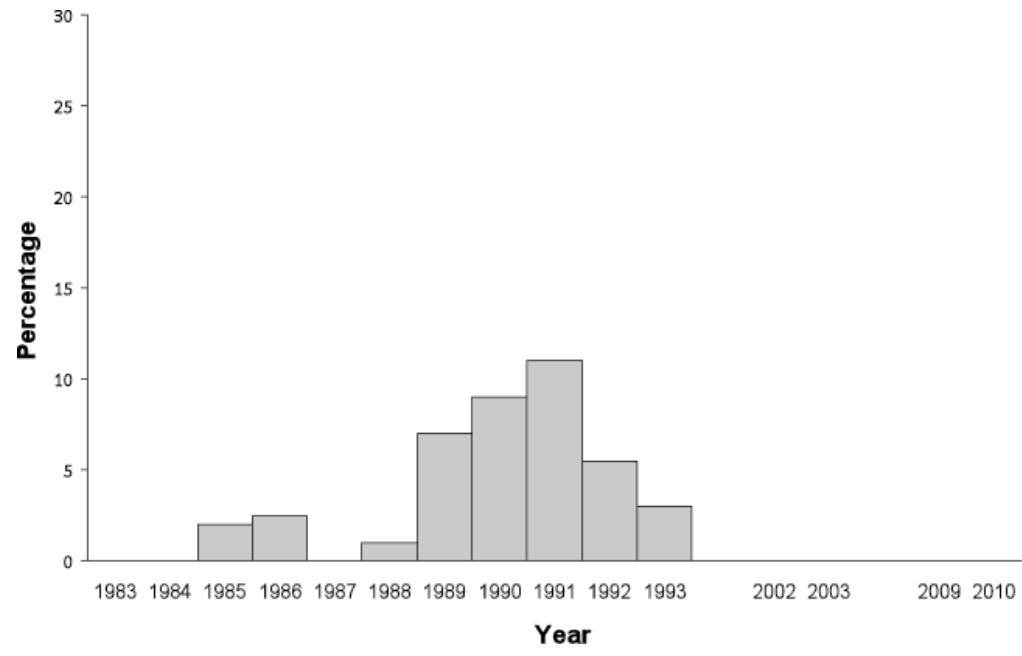

Figure 12: Percentage of papers on self-help groups 


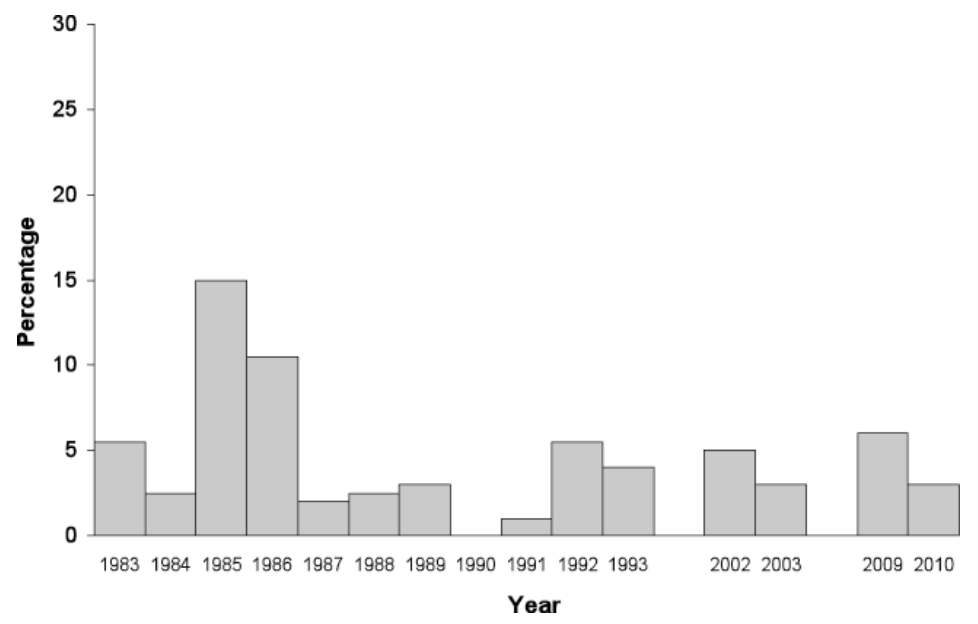

Figure 13: Percentage of papers on historical studies

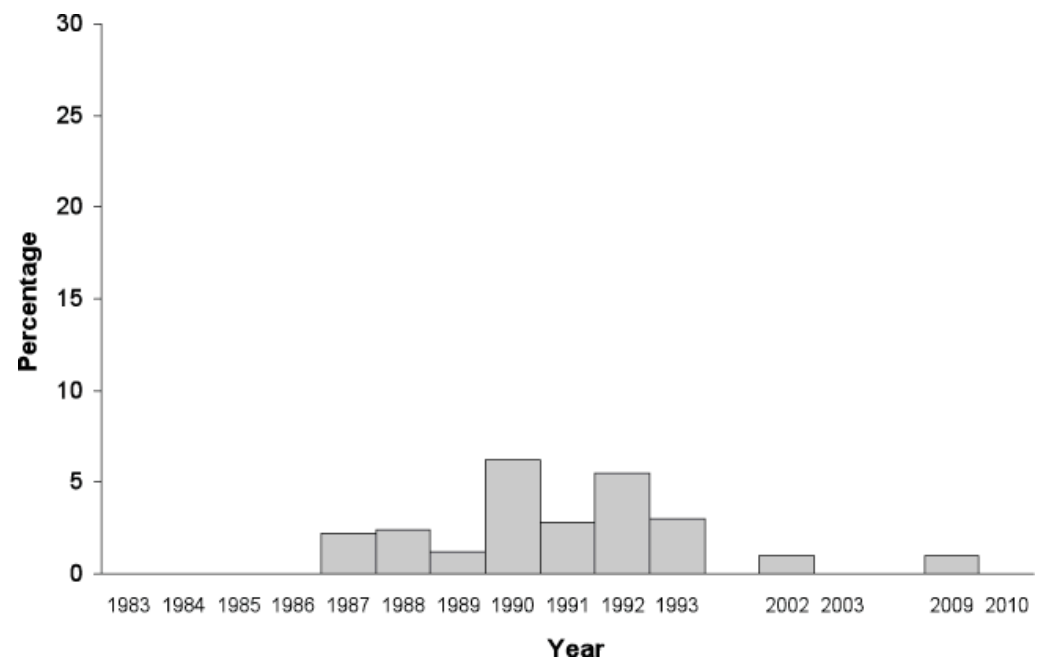

Figure 14: Percentage of papers on alcohol and suicide

\section{Research}

Surveys have been the most popular research method for all years studied, with about $40 \%$ of papers based on surveys (Figure I5). Literature review papers were more predominant between I983 and I993 than in the other time periods; in 2002/2003 and 2009/2010, only a small percentage of papers were based on this method. Compared to the first two research periods, more papers from 2009/2010 used qualitative methods and somewhat fewer papers used existing data sources (Figures I6-I8). In 2009/20I0 almost onequarter of the papers were scored as "other," and many of these papers used multi-method studies (Figure I9). (This category was not used in the classification of papers from 1983 to 1993 and $2002 / 2003$, so comparisons over time for that category are not possible.) 


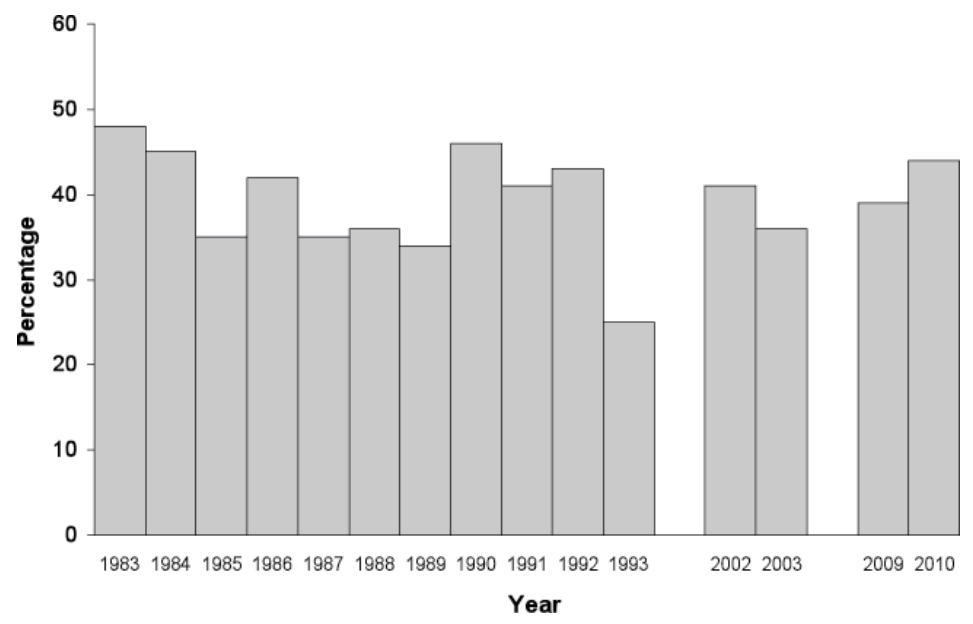

Figure 15: Percentage of papers based on surveys

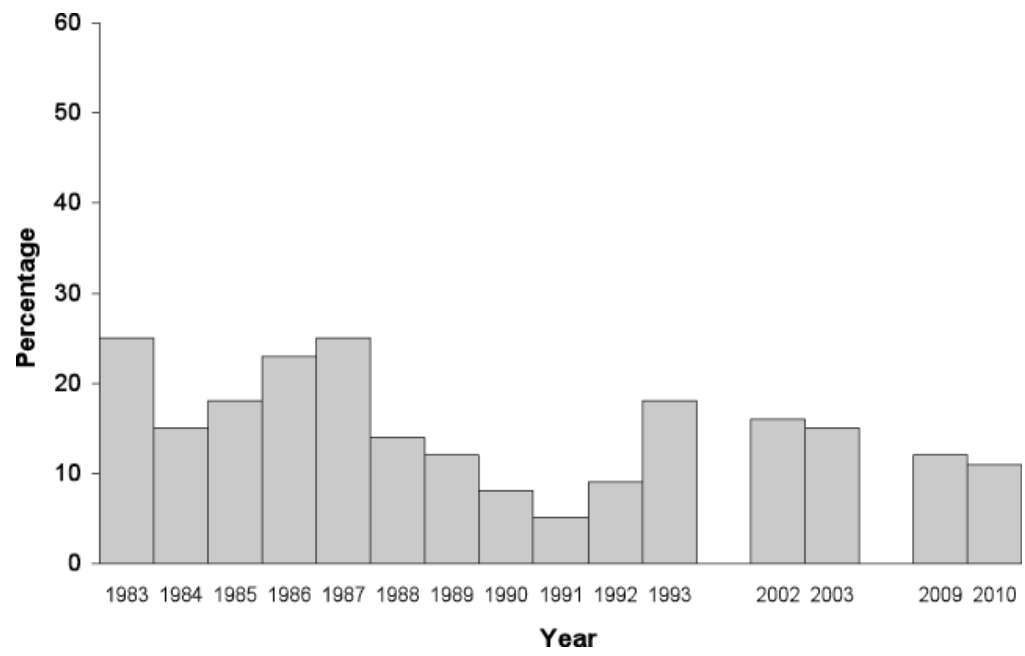

Figure 16: Percentage of papers based on existing sources 


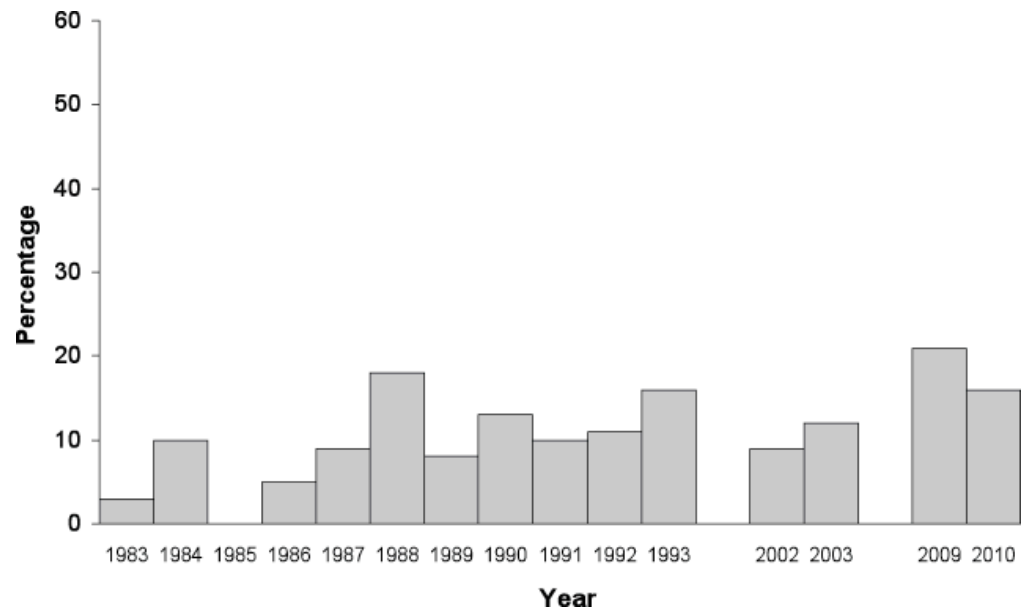

Figure 17: Percentage of papers based on qualitative methods/interviews

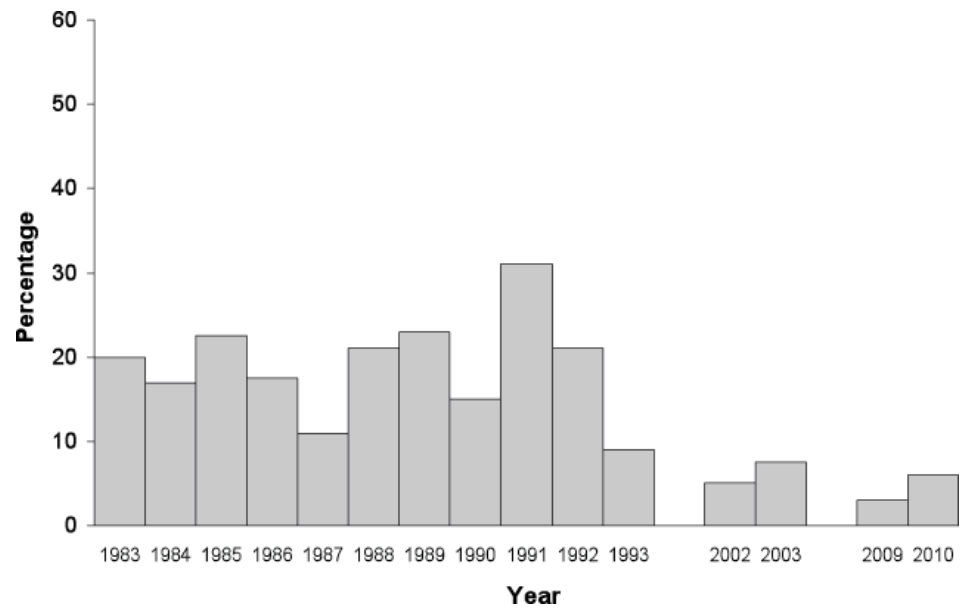

Figure 18: Percentage of papers based on literature/review 


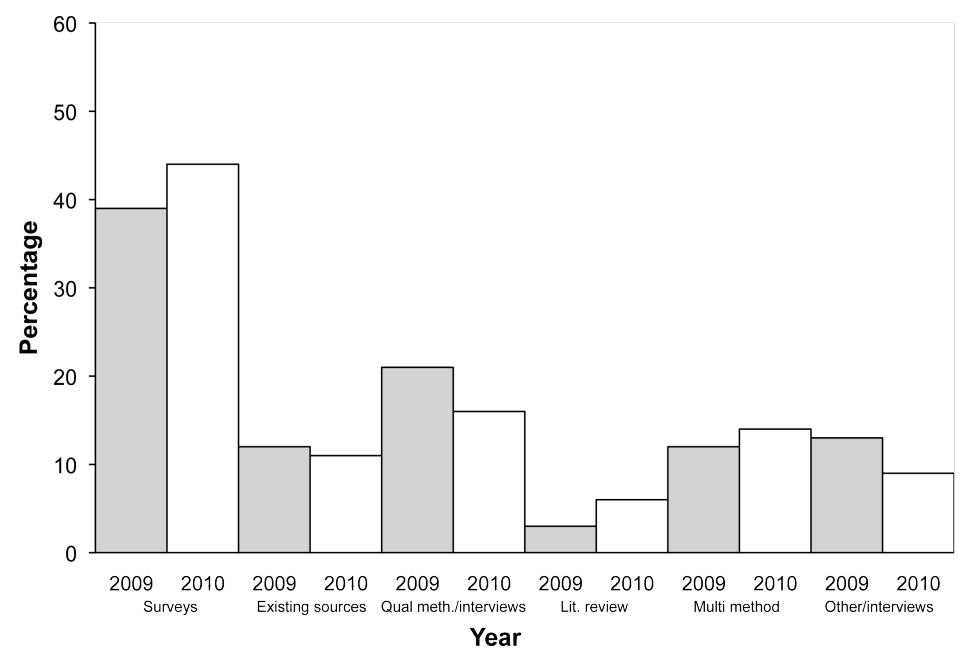

Figure 19: Research methods used 2009/2010

\section{Participants}

As shown in Figure 20, there was a steady increase in the total number of participants between 1987 and I993. The highest number of participants in this period was reached at the $1992 \mathrm{KBS}$ annual meeting in Toronto, Canada ( $\mathrm{N}=\mathrm{I} 84$ ). During subsequent years, this increase continued. By the third time period studied, numbers of participants were consistently over 200: the 2009 meeting in Copenhagen, Denmark, had 239 participants and the 2010 meeting in Lausanne, Switzerland, had 212.

The increase in the percentage of female participants was particularly remarkable. Between I9 83 and 1987 the proportion of female participants varied from one-quarter to one-third of the total number. From I988 to I993 this proportion varied between $40 \%$ and $50 \%$. In $2002 / 2003$ about $55 \%$ of the participants were female, and the figure increased to approximately $60 \%$ by $2009 / 2010$.

\section{Region of origin}

From I983 to 1993 almost all participants came from North America (United States and Canada) and Europe, especially the Nordic countries (Figure 2I). In $2002 / 2003$ and 2009/2010, most participants still came from the Nordic countries and, to a somewhat lesser degree, North America.

In I983 more than half of the participants came from two countries: the United States and Finland. Between I9 83 and I987 the Nordic countries had the highest attendance rates. From i9 88 to I993 the proportion of participants from North America increased, in particular in I988 (Berkeley, United States) and 1992 (Toronto, Canada). 


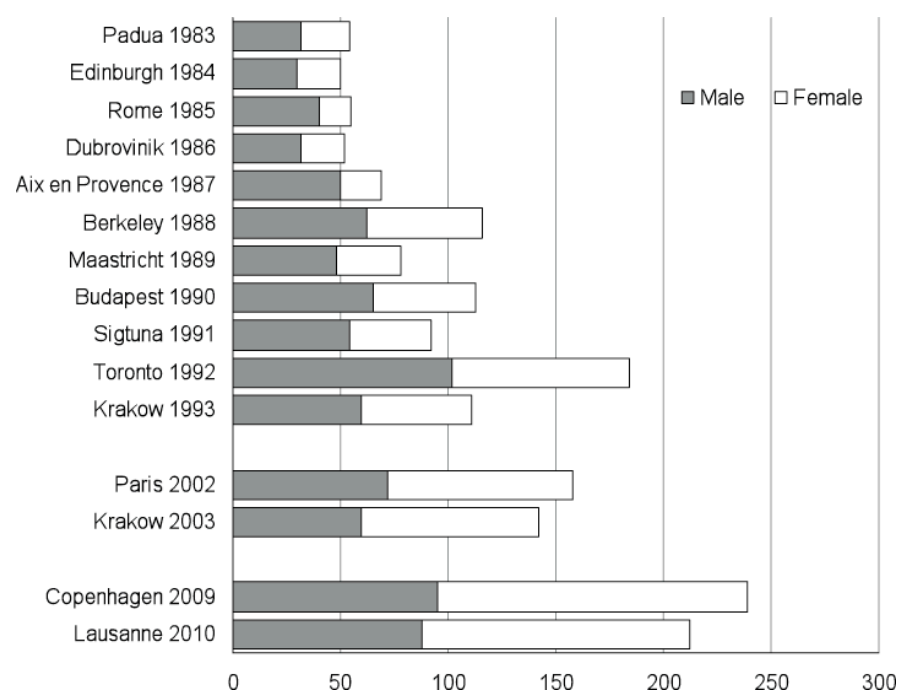

Figure 20: Number of participants of KBS meetings 1983-2010 by sex

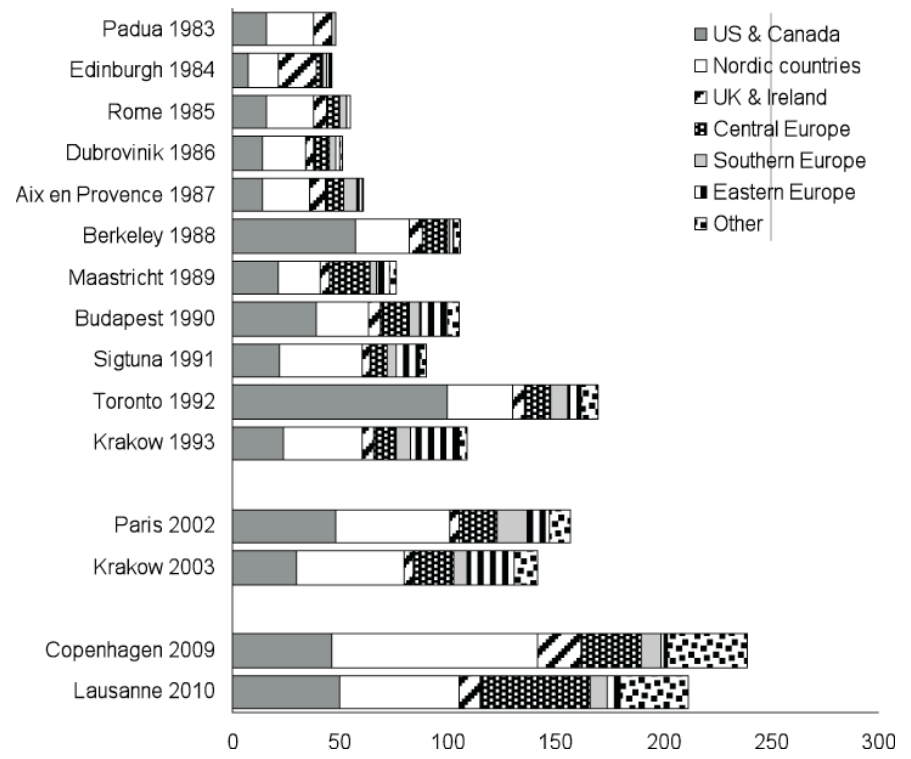

Figure 21: Number of participants of KBS meetings grouped by geographical region

Within the category "Nordic countries," important differences have taken place. In the early years, most Nordic participants came from Finland; however, in 2002, 2003 and 2009, most were from Sweden. In 2010 this variation in country of origin was not so pronounced: most Nordic participants came from Norway (about half of them from Stavanger, the host city for 20I2), followed by Finland, Sweden and Denmark. 
The geographical location of the host city is an important factor. For instance, the number of participants from Eastern Europe was high in 1993 and 2003 (both meetings were held in Krakow, Poland), while the number of participants from midEurope was higher in 2010, when the meeting was held in Lausanne, Switzerland.
Although meetings hosted in North America and Europe continue to have the highest attendance rates, it is notable that in 2009/2010 all continents were represented. This is shown in Figure 22, in which for the years 2009 and 2010 the category "Other" is specified.

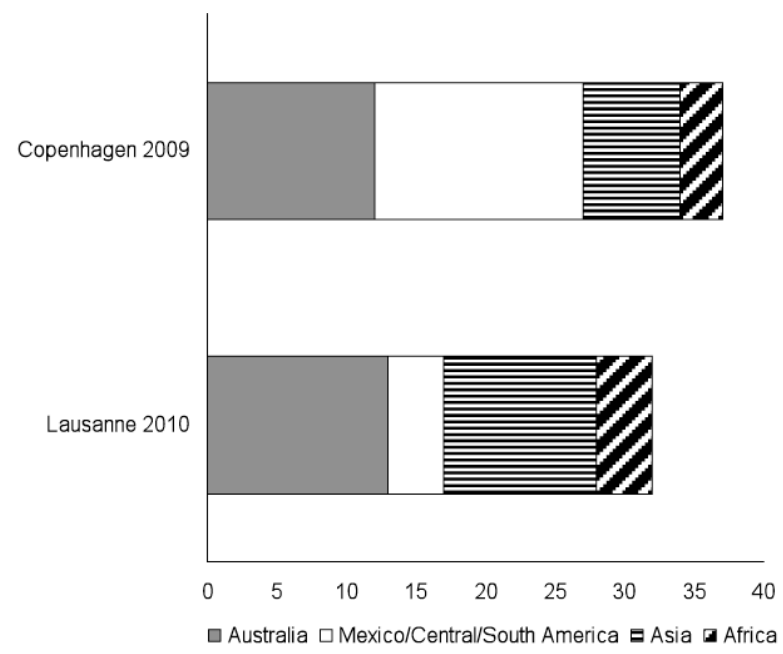

Figure 22: Number of participants KBS meetings grouped by geographical region: specification of the category "Other"

\section{Discussion}

This article covers papers and participants at the annual meetings of the Kettil Bruun Society, and, to some extent, in the field of social and epidemiological research on alcohol in general. The article compares the period I983 to I993 with the years 2002/2003 and 2009/20I0, and examines whether changes have occurred with regard to the content of the papers presented, research methods used, and gender and country of origin of participants.

In all years studied, many papers described general drinking patterns and/or alcohol problems. However, some changes were identified with regard to the research fields addressed. Compared to the years 1983 to 1993 , more papers in $2002 / 2003$ and $2009 / 2010$ dealt with policy, and more papers used explanatory models. In addition, the topics of treatment and care, and norms and attitudes, were a little more prevalent in 2002/2003 and 2009/2010 than in previous years. The proportion of papers on alcohol and drugs fluctuated over the years studied. A number of topics were prevalent during a limited number of years (e.g., alcohol and suicide, and selfhelp groups). This may be explained by the fact that international collaborative projects and presymposium meetings focusing on these topics took place during these years. Why the interest in the topics diminished after the projects were finished is not clear.

In each research period, about $40 \%$ of the papers were based on surveys. Between I983 to I993, a higher proportion of papers were based on literature reviews than in later years. In 2009 and 20I0, somewhat fewer papers were based on existing data sources and more based on qualitative methods than in earlier years. A possible reason for these changes might be increasing attention to multi-method studies and combined quantitative 
and qualitative research. In addition, research methodologies have become more advanced and more varied over the years.

Results show a continuous increase in the number of participants, particularly women. Another positive development is the involvement of researchers from more continents, though the percentage of participants from continents other than Europe and North America is still quite small.

\section{Limitations}

In general the results give a rather good overview of developments in social and epidemiological research on alcohol. However, these analyses have a number of limitations. First, for the period I9 83 to I993 only papers actually presented at the meetings were reviewed, while for the other years all papers included in the abstract lists were taken into account. This is not seen as a serious drawback, however, because only in some exceptional cases was an abstract submitted but the paper not actually presented.

A second limitation concerns presymposium papers. During many meetings presymposia were organized, grouped around specific issues such as gender and alcohol. Papers presented in pre-symposia are not included in the study, though pre-symposia papers that were also presented in the main program of the annual meeting are included.

Third, the review process was undertaken at three different points in time and by different groups of researchers. However, because the principal investigator was the same on all occasions, the same procedures were followed for each analysis.

Fourth, overlaps between categories, such as alcohol problems and alcohol patterns, are difficult to assess. Finally, the fact that over the years the same categories have been used (in order to be able to make comparisons over time) is problematic. This limitation increases in importance over the years. This way of analyzing the topics means that it is possible to check whether "old" topics still are addressed, but "new trends" are not reflected in the results. For instance, with regard to the research methods used in the years 2009 and 2010 respectively, $\mathrm{I} 2 \%$ and $14 \%$ of all papers presented were based on multi-method studies; however, this category was not distinguished in previous years. While including new topics would make comparisons over time difficult, it seems important for the reasons described above to include new topics in any future follow-up studies.

\section{Future prospects}

What will the future bring? Perhaps we will see more research on new topics such as alcohol and violence, and drinking environments, or more multi-method studies. We may also see more collaboration between social scientists and neurobiological researchers, or more research focused on the combination of alcohol and drug use and other risk-taking behavior. We may also see more researchers from a broader range of countries. Monitoring these and other developments in the future would provide further opportunity to analyze developments over time.

\section{References}

Demers, A., Garretsen, H., Room, R., Rossow, I., \& Ugland, T., (2004). Kettil Bruun Society for Social and Epidemiological Research on Alcohol. Addiction, 2 (99), I6I-I64.

Garretsen, H., van Oers, J., \& van de Goor L. (I993, June). The Kettil Bruun Society, the past decade. About booze, what do we choose? Paper presented at the Igth Annual Alcohol Epidemiology Symposium, Krakow, Poland.

Garretsen, H., Bongers, I., van de Goor, L., Roeg, D., (2003, June) The Kettil Bruun Society in the past decades: About booze what do we choose another 10 years later. Paper presented at the 29 th annual alcohol epidemiology symposium, Krakow, Poland, June 2-6, 2003. 